\title{
Fatigue in adults with Osteogenesis Imperfecta
}

\author{
Arjan G. J. Harsevoort ${ }^{1 \dagger}$, Koert Gooijer ${ }^{1 *+} \mathbb{D}$, Fleur S. van Dijk ${ }^{1,2}$, Daniëlle A. F. M. van der Grijn ${ }^{1}$, \\ Anton A. M. Franken ${ }^{1}$, Anne Marieke V. Dommisse ${ }^{1}$ and Guus J. M. Janus ${ }^{1}$
}

\begin{abstract}
Background: Osteogenesis Imperfecta (OI) is characterized by bone fragility, and features such as blue sclerae, dentinogenesis imperfecta, hearing loss, ligamentous laxity and short stature can be present. It has long been assumed that the functional ability and quality of life of patients with OI depends primarily on the severity of skeletal deformities. However, fatigue is often mentioned in clinic by patients with all types of OI as an important modifier of their quality of life and does not always seem to be related to their functional ability. The aim of this study is to investigate whether adults with Osteogenesis Imperfecta are significantly more fatigued than the normal population.

Methods: The Fatigue Severity Scale (FSS) was distributed by mobile phone application among 151 adult patients with different OI types. Results of the FSS in the Ol group were compared with two control populations from America $(n=20)$ and the Netherlands $(n=113)$.

Results: Ninety-nine patients (OI type $1(n=72)$, Ol type $3(n=13)$, Ol type $4(n=14)$ completed the FSS questionnaire. The mean FSS score of this cohort was 4.4 and significantly higher than the control populations (2.3/ 2.9). $65 \%$ of our cohort reported at least moderate fatigue compared with 2 control populations from America and the Netherlands.

Conclusion: Fatigue in patients with $\mathrm{Ol}$ is a frequently encountered problem in our expert clinic but research into this topic is sparse. This pilot study is the largest study to date investigating fatigue in patients with $\mathrm{Ol}$ and results have been compared with two control groups. The mean FSS score of 4.4 in the Ol group indicates that people with Ol are generally significantly more fatigued than the control population. Further evaluation of fatigue and its influencers in a larger group of Ol patients is important for future management.
\end{abstract}

Keywords: Osteogenesis Imperfecta, Fatigue, Fatigue severity scale

\section{Background}

Osteogenesis imperfecta (OI) is a rare hereditary disorder with a prevalence of 6-7:100,000 [1]. OI is primarily characterized by bone fragility. Additional features of OI include blue sclerae, dentinogenesis imperfecta, hearing loss, ligamentous laxity and short stature [2-6]. OI is known to be a clinically variable disorder with severity ranging from perinatal lethality to slightly increased fracture frequency with normal life expectancy [3]. As such, the clinical classification of OI consists of 5 different

\footnotetext{
* Correspondence: k.gooijer@isala.nl

${ }^{\dagger}$ Arjan G. J. Harsevoort and Koert Gooijer contributed equally to this work. ${ }^{1}$ Expert Center for adults with Osteogenesis Imperfecta, Isala Hospital, Zwolle, The Netherlands

Full list of author information is available at the end of the article
}

types (1-5) [6] In approximately $90 \%$ of patients with OI, dominant mutations in the genes COL1A1 and COL1A2 encoding respectively the alpha1 and alpha2 chains of the protein collagen type I, are identified [6]. The functional ability of patients with OI, especially ambulation, have been historically attributed to the severity of the skeletal deformities [3,6] and this has long been the focus of physicians involved in the care of patients with OI. However, many patients visiting our expert center for adults with OI complained about fatigue, which limits their quality of life, and asked whether this could be related to their diagnosis of OI. Previous studies indicate that the quality of life (QoL) of individuals with OI is negatively influenced by reduced function due to

(c) The Author(s). 2019 Open Access This article is distributed under the terms of the Creative Commons Attribution 4.0 International License (http://creativecommons.org/licenses/by/4.0/), which permits unrestricted use, distribution, and reproduction in any medium, provided you give appropriate credit to the original author(s) and the source, provide a link to the Creative Commons license, and indicate if changes were made. The Creative Commons Public Domain Dedication waiver (http://creativecommons.org/publicdomain/zero/1.0/) applies to the data made available in this article, unless otherwise stated. 
fatigue indicating that fatigue is an important factor when considering quality of life in OI patients [7-10]. As such, we approached a subgroup of our total group of OI patients to investigate the impact of fatigue on daily functioning compared to control populations.

\section{Methods}

\section{Study design and population}

A cross-sectional cohort study was undertaken in the national expert center for adult patients with Osteogenesis Imperfecta, Isala Hospital, Zwolle, The Netherlands. All patients who visited the expert center from December 2007 until December 2015 were selected to participate. The main exclusion criteria were unreturned questionnaires. Informed consent was obtained from each participant. The study was registered in the Isala research registry (Nr.190106) and the local Medical Ethical Committee approved the study protocol and granted an exemption because participants are not subject to procedures and are not required to follow rules of behavior.

\section{Data collection}

Many definitions of fatigue exist [11] as well as scales to measure the nature, severity and impact of fatigue in a range of clinical populations [12]. To investigate fatigue in patients with OI the Fatigue Severity Scale (FSS) was distributed among all adult patients. The FSS questionnaire is widely used and has been found valid and reliable in different patient groups [13] It is developed to measure the impact of fatigue on daily functioning [14] and consists of the following nine statements: 1 . My motivation is lower when I am fatigued. 2. Exercise brings on my fatigue. 3. I am easily fatigued. 4. Fatigue interferes with my physical functioning. 5. Fatigue causes frequent problems for me. 6. My fatigue prevents sustained physical functioning. 7. Fatigue interferes with carrying out certain duties and responsibilities. 8. Fatigue is among my three most disabling symptoms. 9. Fatigue interferes with my work, family, or social life. The higher the score (on a scale of 1-7), the higher the impact on fatigue in daily living ( 1 completely disagree, to $7 \mathrm{com}$ pletely agree.)

The questionnaire was sent to the patients in the form of an email containing a link to download a mobile application. If participants were unable to download the application, the questionnaire was sent by email or regular post. To assess how fatigue influences daily living in OI patients we analyzed the distribution of scores for the 9 separate statements. The severity of fatigue was calculated as a mean FSS score of all nine items per patient ranging from 1.0 (no fatigue) to 7.0 (maximum fatigue).

Medical records were analyzed from patients who completed the FSS to determine gender, age and the type of OI according to the updated Sillence criteria [3].
Means and standard deviation (SD) were given for normally distributed continuous variables. Differences in means comparing OI patients and separate FSS questions were tested using independent t-tests and the mean differences were presented as the mean with 95\% confidence intervals $(95 \% \mathrm{CI})$. A two-sided $p$-value of 0.05 was considered significant. All data were analyzed with SPSS (statistics 24.0.)

\section{Control populations}

To evaluate the impact of fatigue on daily living in OI versus controls, we compared the FSS scores from our cohort with two previous studies that used the FSS. The first study by Krupp et al. 1989 [14] investigated fatigue in individuals with MS (multiple sclerosis) and SLE (systemic lupus erythematosus) and in a control group consisting of 20 healthy American individuals selected from volunteers unfamiliar with the study with a mean age of 39.7 years SD 9. The American control group scored a mean of 2.3 SD 0,7. The researchers determined a cut off score $>4$ for severe fatigue, influencing daily living [14]. The second study concerned the study of Merkies et al. 1999 [15] which investigated fatigue in immunemediated polyneuropathies and recruited a Dutch control group $(n=113)$ from hospital personnel, companions (relatives, friends) of patients visiting their outpatient clinic, and volunteers unfamiliar with their study. These patients declared themselves to be healthy, free from any chronic medical condition, and were not taking medication that could contribute to fatigue. This control group consisted of 54 men and 59 women with a mean age of 54.2 (range 18-83) being an average cohort out of the Dutch population and comparable to our OI cohort regarding age and gender distribution. The Dutch control group had a mean and median FSS of 2.9, SD 1.1. Severe fatigue was defined as FSS score $>5.1$ $($ mean $+2 \mathrm{SD})$ and fatigue was defined as FSS score $>4$ (mean $+1 S D, n=113,15]$.

\section{Results}

\section{Clinical characteristics}

We approached 221 OI patients who had visited the expert center to participate in this study and to fill in the questionnaire. The age range of this cohort was $18-80$ years. Permission and signed informed consent were received from 151 patients. A group of 52 patients did not complete the questionnaire and was therefore excluded. Therefore, 99 patients (65.1\% response rate) were available for analysis. It concerned individuals with type 1 $(n=72)$, type $3(n=13)$ and type $4(n=14)$. Sixty-one women and 38 men were included. The mean age was 45 (age range 19-80 years). These distributions are comparable to our total OI population [16]. 


\section{Fatigue severity score}

\section{Participant basic characteristics and total scores}

The mean and median FSS score of the individuals with OI in our cohort were respectively 4.4 and 4.8, SD 1.4 (95\% CI 4.16-4.70). According to the KolmogorovSmirnov test, the distribution of the FSS mean score was normal $(P=0.105) .42 \%(n=42)$ of the respondents had a mean FSS score of $\geq 5$ whilst $23.1 \%(n=23)$ had a mean FSS score between 4 and 5 . The man/woman distribution in the cohort was $40.5 \%(n=17) / 59.5 \%(n=25)$.

A single sample t-test and the Mann-Whitney $U$ test were conducted to determine if the differences between the FSS score in the OI group versus the American and Dutch controls were statistically significant, concluding that individuals with $\mathrm{OI}$ in this cohort have statistically higher fatigue scores than the American control group, $\mathrm{t}(98)=[15.46], p=[0.000]$, and the Dutch control group, $\mathrm{t}(98)=[11.10], p=[0.000]$.

Statements 3 and 4 of the FSS had both higher median scores with a smaller $95 \%$ confidence interval of the mean (4.63 CI 4.27-4.99 and 4.66 CI 4.32-4.99) (significance $0.099,0.067)$ compared to the other questions. Statements 6 and 8 had also a high median score $(4.23,4.67)$, but overall more diffuse results as can be seen in the $95 \%$ confidence interval (3.86-4.7; 4.22-5.12) (Table 1).

\section{Gender differences}

Table 1 shows that there were no significant differences per gender with regard to the total FSS score. Women scored higher $(4.56 \pm 1.22)$ than men $(4.22 \pm 1.57)$ on the total FSS score and also in all separate statements except statement 1 . On statement 8 this difference was significant. (w:5.03 $\pm 2.08, \mathrm{~m}: 4.08 \pm 2.42(p=0.048)$.

\section{Age group distribution}

A visual comparison of the separate FSS scores between the different age categories is shown in Fig. 1. The FSS score for question 1 in age category 41-45 is significantly lower (2.4) than the remainder age categories in our study cohort (5.8). (independent T-test $p=0,000$ ). All other comparison did not reveal significantly different values.

\section{Differences between types of $\mathrm{OI}$}

There were no significant differences per OI type for the mean FSS score. The FSS mean scores were in all OI types $\geq 4$ (Table 2 ).

There were no significant differences per OI type for the separate FSS statements (data not shown). In the group with a mean FSS $\geq 5$, the distributions regarding OI type were: OI type 1: $64.3 \%(n=27)$, OI type $3: 13.4 \%(n=6)$, OI type 4 : $21.4 \%(n=9)$. People with OI type 4 scored higher than people with OI type 3 and OI type 1 on question 3,6 and 8 .

\section{Discussion}

Fatigue is often mentioned by individuals with OI during the clinical appointment. As the prevalence and experience of fatigue in patients with OI is largely unknown, we set out to perform a pilot study regarding occurrence and severity of fatigue in people with OI to determine whether this needs to be explored further. 99/151 patients filled in the FSS. We assessed the medical records for age, gender and type of OI. We did not analyze for any medical confounders such as recent fracture(s), cardiac or lung complications, initiated therapy, physical exertion, mobility and work. The mean and median FSS score of the individuals with OI was respectively 4.4 and 4.8 .

\section{FSS results compared to results in two control groups}

The fatigue scores in our study cohort are significantly higher compared to the Dutch national control $\operatorname{group}(n=$ 113) [15] and the American control group $(n=20)$ [14]. Merkies et al. [11] define a mean FSS score $\geq 5.1$ as severe fatigue, and a score $>4$ and $<5$ equates "borderline fatique "[15]. When analysing the FSS results of the OI cohort

Table 1 Mean score per FSS statement for the whole Ol group and according to gender

\begin{tabular}{|c|c|c|c|c|c|}
\hline $\begin{array}{l}\text { FSS } \\
\text { Statements }\end{array}$ & Mean score & 95\% Confidence interval & Mean men & Mean women & $\begin{array}{l}\text { Difference gender } \\
\text { signific. (independent } \\
\text { t-test) }\end{array}$ \\
\hline 1 & 5.43 & $5,14-5,59$ & $5.47 \pm 1.67$ & $5.41 \pm 1.38$ & 0.837 \\
\hline 2 & 4.16 & $3,82-4,5$ & $4.03 \pm 1.76$ & $4.25 \pm 1.69$ & 0.538 \\
\hline 3 & 4.63 & $4,27-4,99$ & $4.21 \pm 1.99$ & $4.89 \pm 1.63$ & 0.069 \\
\hline 4 & 4.66 & $4,32-4,99$ & $4.58 \pm 1.87$ & $4.70 \pm 1.56$ & 0.719 \\
\hline 5 & 3.71 & $3,36-4,06$ & $3.66 \pm 2$ & $3.74 \pm 1.6$ & 0.836 \\
\hline 6 & 4.23 & $3,86-4,7$ & $4.16 \pm 2.4$ & $4.36 \pm 1.92$ & 0.661 \\
\hline 7 & 4.14 & $3,75-4,53$ & $3.89 \pm 2.12$ & $4.3 \pm 1.82$ & 0.320 \\
\hline 8 & 4.67 & $4,22-5,12$ & $4.08 \pm 2.42$ & $5.03 \pm 2.08$ & 0.048 \\
\hline 9 & 4.19 & $3,77-4,62$ & $3.87 \pm 2.26$ & $4.39 \pm 2.04$ & 0.338 \\
\hline Total & 4.43 & $4.16-4.7$ & $4.22 \pm 1.57$ & $4.56 \pm 1.22$ & 0.234 \\
\hline
\end{tabular}




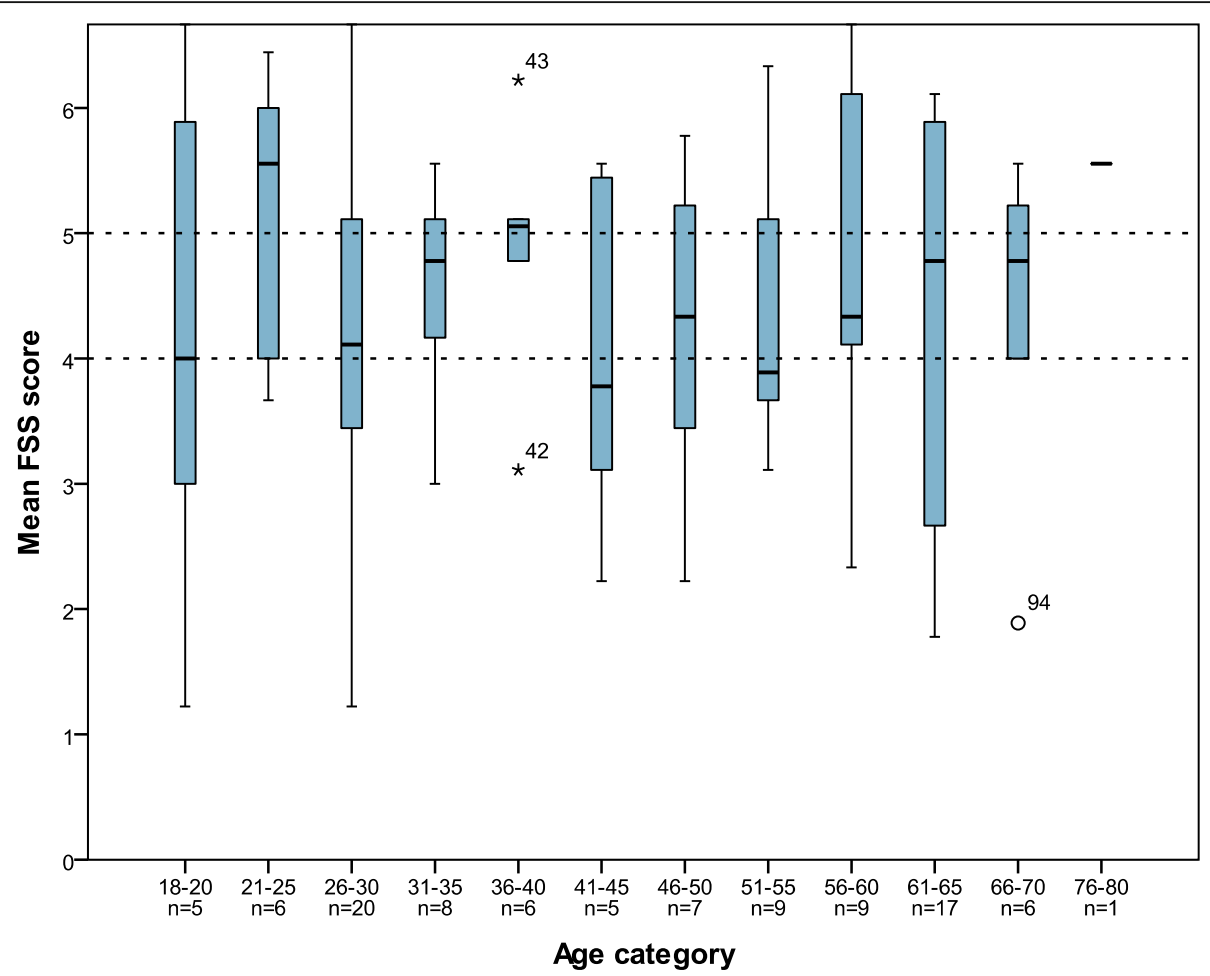

Fig. 1 FSS score per age with marking of moderate and high fatigue scores according to Krupp et al

according to the definitions of Merkies et al. the OI cohort experiences borderline fatigue, influencing daily living, with regard to the mean FSS score.

Krupp et al. [14] defined a FSS score of $>4$ as moderate to high fatigue level, influencing daily living. When analyzing the FSS results according the definition of Krupp et al. [14] it appears that $42.4 \%$ of the respondents $(n=42)$ had a mean FSS score of five or higher indicating severe fatigue. 23.1\% $(n=23)$ had a score between four and five indicating borderline fatigue. When analysing the results with the definition of Merkies et al., it appears that $38.4 \%$ of the respondents $(n=$ 38) had a mean FSS score of five or higher indicating severe fatigue. 27.3\% $(n=27)$ had a score between 4 and 5.1, indicating borderline fatigue. These mean FSS scores are very high compared to the general population, with only $5 \%$ of the general population being severely fatigued [15]. The presence and severity of fatigue is almost equal across all OI types, which could indicate that OI type and severity of OI is not influencing fatigue. This may demonstrate that although most people with OI type 1 will have reached a higher level of daily functioning than patients with OI type 3 and 4 , they still

Table 2 Mean total FSS score per OI type

\begin{tabular}{lll}
\hline & Mean FSS score & Standard Deviation \\
\hline Ol type $1 N=72$ & 4.38 & 1.36 \\
Ol type $3 N=13$ & 4.33 & 1.69 \\
Ol type $4 N=14$ & 4.75 & 1.14 \\
\hline
\end{tabular}

experience comparable impact of fatigue on their daily functioning. The FSS scores in the OI cohort also exceed minimal clinically important difference (MCID) values determined for other patient groups, which are for example 0.4 for SLE and 0.7 for RA (rheumatoid arthritis) $[17,18]$. Given the above, there appears to be sufficient evidence for the presence of increased occurrence and severity of fatigue in OI patients in the investigated cohort.

\section{FSS results compared to one similar study involving OI patients}

A comparable study was recently performed in Norway by Arponen et al. [9]. It concerned a cross-sectional study of responses of OI patients matched with healthy controls from Norway to a questionnaire, designed to evaluate levels of experienced fatigue and body pain as well as presence or absence of symptoms related to sleep disturbance or sleep apnoea. Fatigue was evaluated with, among others, the FSS questionnaire which demonstrated a FSS mean score of 5 in patients with $\mathrm{OI}(n=56)$. Interestingly, the Norwegian control group scored a mean FSS score of $4(n=56)$. Arponen et al. concluded that in comparison with age and gender matched controls, adults with OI do not differ in experienced fatigue [9].

The Dutch control group [15], has a lower mean FSS score $(2.9, n=113)$ than the control group in the Norwegian study of Arponen et al.(4.0, $n=56,9]$. Compared to the American original validation [14] who report a mean 
FSS of $2.3 \pm 0.7(n=20)$ again the mean FSS score in the Norwegian control group is high.

However, there may be an explanation for the high score in the control group as a Norwegian national study investigating fatigue in the general population, [19] concluded that the high FSS scores in the general population of Norway can be due to difficulties in translation of the US-English version of the FSS into Norwegian because of lack of the concept of fatigue in Norwegian language [19]. A valid comparison between Norway, the Netherlands and the US regarding the FSS may therefore not be possible. A validation of the FSS in a Swiss control group is comparable to the Dutch and American results with a mean FSS score of $3.00 \pm 1.08, \quad(n=454)$ [20]. As such, we can conclude that the mean FSS score of our Dutch control group is comparable with the American and Swiss control groups and that our earlier conclusion that the severity of fatigue is increased in the Dutch OI cohort still holds true.

\section{Limitations of this study and further directions for research}

There is a low response rate $(151 / 221$ gave consent and 99/151 filled in the FSS) when looked at the initially approached patients. It is difficult to speculate why this could be the case but an important factor may be that with regard to consent as well as with regard to filling in the FSS, patients were only approached once and were not sent reminder(s). Biases are difficult to avoid as it may be that the people who felt that fatigue was influencing there life significantly, were more inclined to participate but it is also possible that these patients were limited by fatigue to participate in the study. As mentioned before, there are many scales to measure the nature, severity and impact of fatigue in a range of clinical populations and a limitation of the FSS is that it is a general questionnaire, and as such not specially developed for OI. The FSS however explores the severity of fatigue and is therefore suitable for initial screening in different clinical populations and can be used for longitudinal measurements which is important in assessing whether fatigue can increase or decrease over time and exploring possible modifiers of fatigue. Another limitation of our study lies with the control populations as both the Dutch control group and the US control group date from respectively 1999 and 1989 and trends in fatigue may change in the population over time.

Lastly, we did not investigate any factors that influence fatigue in OI patients in our study, but this is an important direction for further research into fatigue in patients with OI as fatigue may influence QOL. Other factors have been reported as well [21]. It is already known that the presence of pain, but also educational level and employment status influence the severity of fatigue. Bathmen et al. published on fatigue in Marfan syndrome, another hereditary connective tissue disorder. The authors concluded that occurrence of chronic pain and employment status influenced the severity of fatigue [22]. Interestingly, a study in children with OI reported a decrease of the level of fatigue after a 12-week individual and supervised physical training program, and increase of the level of fatigue after the program had stopped [10, 23]. Studies in other patient groups, including people with Marfan syndrome reported good effects of physical activity on fatigue [24-26]. This is important knowledge since some OI patients or parents of OI patients tend to limit their physical activity when they become aware of the inherited bone fragility [23]. Some age categories may benefit from an individual and supervised training program.

\section{Conclusion}

In this study the influence of fatigue on daily functioning was investigated in the largest cohort of OI patients to date and compared with control groups in particular a national control group. Although, there were several limitations of our study, based on the current data, there is sufficient evidence for increased severity of fatigue in our cohort of OI patients. An important direction for future research is performing longitudinal measurements using the FSS and exploring determinants of fatigue as this may be of importance for the quality of life in OI patients.

\section{Abbreviations \\ 95\%Cl: 95\% confidence interval; FSS: Fatigue severity scale; MCID: Minimal clinically important difference values; MFS: Marfan syndrome; MS: Multiple sclerosis; Ol: Osteogenesis Imperfecta; QOL: Quality of life; RA: Rheumatoid arthritis; SD: Standard deviation; SLE: Systemic lupus erythematosus}

\section{Acknowledgements}

We thank the people with Ol for their participation.

\section{Authors' contributions}

AGJH and AMVD developed the idea for the study and GJMJ and AAMF led on research governance. AGJH designed the research, took care of the ethical approval, and he and KG performed the literature search. KG performed statistical analysis and DAFMG AGJH and KG wrote the manuscript. AGJH and DAFMG enrolled the patients and collected the data. KG performed, analysed and interpreted the tests. FSD extensively and critically reviewed the draft of the manuscript. All authors critically revised the work, providing substantial input, and gave final approval of the version to be published.

\section{Authors' information}

A.G.J.H. Advanced nurse practitioner, K.G. MSc. Research Physician, F.S.D. clinical geneticist, D.A.F.M.G. occupational therapist, A.A.M.F. Endocrinologist, A.M.V.D. rehabilitation specialist, G.J.M.J. Orthopaedic surgeon.

\section{Funding}

This work was supported by a grant from the Care 4 Brittle Bones foundation for the development of the mobile questionnaire application. This mobile application made the questionnaire more accessible to the patients but had no consequences for the interpretation of the data and the writing of the manuscript. Care 4 Brittle Bones had no involvement in the design of the study, collection, analysis and interpretation of the data or in writing the manuscript. 


\section{Availability of data and materials}

The datasets used and analysed during the current study are available from the corresponding author on reasonable request.

\section{Ethics approval and consent to participate}

The study was registered in the Isala research registry (Nr.190106) and the local Medical Ethical Committee approved the study protocol and granted an exemption because participants are not subject to procedures or are required to follow rules of behavior. A signed informed consent was obtained from each participant.

\section{Consent for publication}

Not applicable.

\section{Competing interests}

The authors declare that they have no competing interests.

\section{Author details}

'Expert Center for adults with Osteogenesis Imperfecta, Isala Hospital, Zwolle, The Netherlands. ${ }^{2}$ North West Thames Regional Genetics Service, Ehlers-Danlos Syndrome National Diagnostic Service London, North West Health Care NHS Trust, Harrow, Middlesex, UK.

Received: 25 April 2019 Accepted: 11 December 2019

Published online: 03 January 2020

\section{References}

1. Steiner RD, Basel D. COL1A1/2 Osteogenesis Imperfecta. [Updated 2019 Dec 12]. In: Adam MP, Ardinger HH, Pagon RA, et al., editors. GeneReviews ${ }^{\oplus}$ [Internet]. Seattle (WA): University of Washington, Seattle; 2005. p. 19932019.

2. Sillence DO, Senn A, Danks DM. Genetic heterogeneity in osteogenesis imperfecta. J Med Genet. 1979;16:101-16.

3. Van Dijk FSS, Sillence DOO. Osteogenesis imperfecta: clinical diagnosis, nomenclature and severity assessment. Am J Med Genet Part A. 2014;164: 1470-81.

4. Rauch F, Glorieux F. Ostegenesis Imperfecta. Lancet. 2004;363(9418):137785.

5. Glorieux FH. Osteogenesis imperfecta. Best Pract Res Clin Rheumatol. 2008; 22:85-100.

6. Van Dijk FS, Byers PH, Dalgleish R, Malfait F, Maugeri A, Rohrbach M, Symoens $S$, Sistermans EA, Pals G. EMQN best practice guidelines for the laboratory diagnosis of osteogenesis imperfecta. Eur J Hum Genet. 2012;(1): $11-9$.

7. Hill CL, Baird WO, Walters SJ. Quality of life in children and adolescents with Osteogenesis Imperfecta: a qualitative interview based study. Health Qual Life Outcomes. 2014;12:54.

8. Tosi LL, Oetgen ME, Floor MK, Huber MB, Kennelly AM, McCarter R, Rak MF, Simmonds BJ, Simpson MD, Tucker CA, McKiernan FE. Initial report of the osteogenesis imperfecta adult natural history initiative. Orphanet J Rare Dis. 2015;10: 146.

9. Arponen H, Waltimo-Sirén J, Valta H, Mäkitie O. Fatigue and disturbances of sleep in patients with osteogenesis imperfecta - A cross-sectional questionnaire study. BMC Musculoskelet Disord. 2018;19(1):3.

10. Van Brussel M, Takken T, Uiterwaal CSPM, Pruijs HJ, Van der Net J, Helders PJM, Engelbert RHH. Physical Training in Children with Osteogenesis Imperfecta. J Pediatr. 2008;152:111-6 e1.

11. Finsterer J, Mahjoub SZ. Fatigue in healthy and diseased individuals. Am J Hosp Palliat Med. 2014;31:562-75.

12. Dittner AJ, Wessely SC, Brown RG. The assessment of fatique: a practical guide for clinicians and researchers. J Psychosom Res. 2004;56:157-70.

13. Whitehead $\mathrm{L}$. The measurement of fatigue in chronic illness: a systematic review of unidimensional and multidimensional fatigue measures. J Pain Symptom Manag. 2009;37:107-28.

14. Krupp LB, Larocca NG, Muir Nash J, Steinberg AD. The fatigue severity scale: Application to patients with multiple sclerosis and systemic lupus erythematosus. Arch Neurol. 1989;46(10):1121-3.

15. Merkies IS, Schmitz PI, Samijn JP, van der Meché FG, van Doorn PA. Fatigue in immune-mediated polyneuropathies. European Inflammatory Neuropathy Cause and Treatment (INCAT) Group. Neurology. 1999;53(8):1648-54.
16. Scheres LJJ, van Dijk FS, Harsevoort AJ, van Dijk ATH, Dommisse AM, Janus GJM, Franken AAM. Adults with osteogenesis imperfecta: clinical characteristics of 151 patients with a focus on bisphosphonate use and bone density measurements. Bone Reports Elsevier. 2018;8:168-72.

17. Pouchot J, Kherani RB, Brant R, Lacaille D, Lehman AJ, Ensworth S, Kopec J, Esdaile JM, Liang MH. Determination of the minimal clinically important difference for seven fatigue measures in rheumatoid arthritis. J Clin Epidemiol. 2008;61(7):705-13.

18. Goligher EC, Pouchot J, Brant R, Kherani RB, Aviña-Zubieta JA, Lacaille D, Lehman AJ, Ensworth S, Kopec J, Esdaile JM, Liang MH. Minimal clinically important difference for 7 measures of fatigue in patients with systemic lupus erythematosus. J Rheumatol. 2008;35(4):635-42.

19. Lerdal A, Moum T, Wahl AK, Rustøen T, Hanestad BR. Fatigue in the general population: A translation and test of the psychometric properties of the Norwegian version of the fatigue severity scale. Scand J Public Health. 2005; 33(2):123-30.

20. Valko PO, Bassetti CL, Bloch KE, Held U, Baumann CR. Validation of the fatigue severity scale in a Swiss cohort. Sleep. 2008;31(11):1601-7.

21. Hald JD, Folkestad L, Harsløf T, Brixen K, Langdahl B. Health-related quality of life in adults with Osteogenesis Imperfecta. Calcif Tissue Int Springer US. 2017;101:473-8.

22. Bathen T, Velvin G, Rand-Hendriksen S, Robinson HS. Fatigue in adults with Marfan syndrome, occurrence and associations to pain and other factors. Am J Med Genet Part A. 2014;164A(8):1931-9.

23. Mueller B, Engelbert R, Baratta-Ziska F, Bartels B, Blanc N, Brizola E, Fraschini P, Hill C, Marr C, Mills L, Montpetit K, Pacey V, Molina MR, Schuuring M, Verhille C, de Vries O, Yeung EHK, Semler O. Consensus statement on physical rehabilitation in children and adolescents with osteogenesis imperfecta. Orphanet J Rare Dis BioMed Central. 2018;13:158.

24. Dalgas U, Stenager E, Jakobsen J, Petersen T, Hansen HJ, Knudsen C, Overgaard K. Fatigue, mood and quality of life improve in MS patients after progressive resistance training. Mult Scler. 2010;16(4):480-90.

25. Neill J, Belan I, Ried K. Effectiveness of non-pharmacological interventions for fatigue in adults with multiple sclerosis, rheumatoid arthritis, or systemic lupus erythematosus: a systematic review. J Adv Nurs. 2006;56(6):617-35.

26. Peters KF, Kong F, Horne R, Francomano CA, Biesecker BB. Living with Marfan syndrom I. Perceptions of the condition. Clin Genet. 2001;60(4):27382.

\section{Publisher's Note}

Springer Nature remains neutral with regard to jurisdictional claims in published maps and institutional affiliations.

\section{Ready to submit your research? Choose BMC and benefit from:}

- fast, convenient online submission

- thorough peer review by experienced researchers in your field

- rapid publication on acceptance

- support for research data, including large and complex data types

- gold Open Access which fosters wider collaboration and increased citations

- maximum visibility for your research: over $100 \mathrm{M}$ website views per year

At BMC, research is always in progress.

Learn more biomedcentral.com/submissions 